\title{
Pulmonary arterial hypertension treatment with carvedilol for heart failure: a randomized controlled trial
}

\author{
Samar Farha, ${ }^{1}$ Didem Saygin, ${ }^{1}$ Margaret M. Park, ${ }^{1,2}$ Hoi I. Cheong, ${ }^{1}$ Kewal Asosingh, ${ }^{1}$ \\ Suzy A.A. Comhair, ${ }^{1}$ Olivia R. Stephens, ${ }^{1}$ Emir C. Roach, ${ }^{1}$ Jacqueline Sharp, ${ }^{1}$ Kristin B. Highland, ${ }^{3}$ \\ Frank P. DiFilippo, ${ }^{4}$ Donald R. Neumann, ${ }^{4}$ W.H. Wilson Tang, ${ }^{2}$ and Serpil C. Erzurum ${ }^{1,3}$ \\ 'Lerner Research Institute, ${ }^{2} \mathrm{Heart}$ and Vascular Institute, ${ }^{3}$ Respiratory Institute, and ${ }^{4}$ Imaging Institute, Cleveland Clinic, \\ Cleveland, Ohio, USA.
}

BACKGROUND. Right-sided heart failure is the leading cause of death in pulmonary arterial hypertension (PAH). Similar to left heart failure, sympathetic overactivation and $\beta$-adrenoreceptor ( $\beta A R$ ) abnormalities are found in PAH. Based on successful therapy of left heart failure with $\beta$-blockade, the safety and benefits of the nonselective $\beta$-blocker/vasodilator carvedilol were evaluated in PAH.

METHODS. PAH Treatment with Carvedilol for Heart Failure (PAHTCH) is a single-center, doubleblind, randomized, controlled trial. Following 1-week run-in, 30 participants were randomized to 1 of $\mathbf{3}$ arms for $\mathbf{2 4}$ weeks: placebo, low-fixed-dose, or dose-escalating carvedilol. Outcomes included clinical measures and mechanistic biomarkers.

RESULTS. Decreases in heart rate and blood pressure with carvedilol were well tolerated; heart rate correlated with carvedilol dose. Carvedilol-treated groups had no decrease in exercise capacity measured by 6-minute walk, but had lower heart rates at peak and after exercise, and faster heart rate recovery. Dose-escalating carvedilol was associated with reduction in right ventricular (RV) glycolytic rate and increase in $\beta A R$ levels. There was no evidence of RV functional deterioration; rather, cardiac output was maintained.

CONCLUSIONS. Carvedilol is likely safe in PAH over 6 months of therapy and has clinical and mechanistic benefits associated with improved outcomes. The data provide support for longer and larger studies to establish guidelines for use of $\beta$-blockers in PAH.

TRIAL REGISTRATION. ClinicalTrials.gov NCT01586156

FUNDING. This project was supported by NIH R01HL115008 and R01HL60917 and in part by the National Center for Advancing Translational Sciences, UL1TR000439.

Role of funding source: Funding supported the entire trial, including visits, clinical and experimental testing, and effort of investigators.

Conflict of interest: The authors have declared that no conflict of interest exists.

Submitted: May 19, 2017

Accepted: July 18, 2017

Published: August 17, 2017

Reference information:

JCI Insight. 2017;2(16):e95240.

https://doi.org/10.1172/jci.

insight.95240.

\section{Introduction}

Pulmonary arterial hypertension $(\mathrm{PAH})$ is a progressive disease of the pulmonary vasculature leading to elevated pulmonary pressure and right ventricular (RV) dysfunction with heart failure. Heart failure is the leading cause of death in PAH. Measures of RV function are better predictors of mortality and longterm outcomes than pulmonary vascular resistance. The RV dysfunction can progress independent of, and despite achieving therapeutic reduction in pulmonary vascular resistance with pulmonary vasodilators (1) The interaction between RV function and the pulmonary circulation is not fully understood, but increased afterload appears insufficient to explain right heart failure (2). Yet, all approved PAH therapies target vasodilation of the pulmonary vasculature to lower pressures.

In contrast to the lack of RV-targeted therapy for the heart failure of PAH, left ventricular-targeted (LV-targeted) therapy has been the foundation of left-sided or global heart failure for nearly 40 years (3). $\beta$-Adrenergic receptor ( $\beta A R$ ) blockade, the cornerstone therapy in left heart failure, reverses cardiac remodeling, and improves clinical outcomes, despite decades of concern regarding its propensity to exacerbate heart failure. Importantly, $\beta$-blockade reduces mortality by nearly $30 \%$ and remains the 
Table 1. Demographics and baseline characteristics

\begin{tabular}{|c|c|c|c|c|c|c|}
\hline & Placebo & $\begin{array}{l}\text { Low-fixed-dose } \\
\text { Carvedilol }\end{array}$ & $\begin{array}{l}\text { Escalating-dose } \\
\text { Carvedilol }\end{array}$ & $P$ value ${ }^{A}$ & Controls & $P$ value ${ }^{B}$ \\
\hline Characteristic & $n=10$ & $n=10$ & $n=10$ & & $n=12$ & \\
\hline Age (years) & $38 \pm 14$ & $42 \pm 6$ & $53 \pm 9$ & 0.006 & $42 \pm 12$ & 0.02 \\
\hline Race & & & & 0.08 & & 0.1 \\
\hline Caucasian, $n(\%)$ & $6(60 \%)$ & $7(70 \%)$ & $10(100 \%)$ & & $11(72 \%)$ & \\
\hline African American, $n$ (\%) & $4(40 \%)$ & $2(20 \%)$ & 0 & & $1(8 \%)$ & \\
\hline Female, $n(\%)$ & $8(80 \%)$ & $7(70 \%)$ & $6(60 \%)$ & & $10(83 \%)$ & \\
\hline Male, $n(\%)$ & $2(20 \%)$ & $3(30 \%)$ & $4(40 \%)$ & & $2(17 \%)$ & \\
\hline Height (cm) & $166 \pm 9$ & $165 \pm 10$ & $171 \pm 9$ & 0.4 & $167 \pm 6$ & 0.5 \\
\hline Weight (kg) & $78 \pm 15$ & $76 \pm 17$ & $94 \pm 23$ & 0.09 & $71 \pm 15$ & 0.03 \\
\hline Temperature $\left({ }^{\circ} \mathrm{F}\right)$ & $97.6 \pm 0.5$ & $97.1 \pm 0.8$ & $97.3 \pm 1.0$ & 0.5 & $97.4 \pm 0.7$ & 0.7 \\
\hline Associated & $2(20 \%)$ & $1(10 \%)$ & $2(20 \%)$ & & & \\
\hline $\begin{array}{l}\text { Pulmonary hypertension due to lung diseases and/or } \\
\text { hypoxia, } n(\%)\end{array}$ & 0 & $2(20 \%)$ & 0 & & & \\
\hline $\begin{array}{l}\text { Chronic thromboembolic pulmonary hypertension, } \\
n(\%)\end{array}$ & $1(10 \%)$ & 0 & $1(10 \%)$ & & & \\
\hline \multicolumn{7}{|l|}{ PAH-specific therapies } \\
\hline $\begin{array}{l}\text { Phosphodiesterase type } 5 \text { inhibitors/stimulator of } \\
\text { soluble guanylate cyclase, } n(\%)\end{array}$ & $7(70 \%)$ & $9(90 \%)$ & $8(80 \%)$ & NA & NA & NA \\
\hline Endothelin receptor antagonist, $n(\%)$ & $5(50 \%)$ & $7(70 \%)$ & $7(70 \%)$ & NA & & \\
\hline Prostacyclin/prostacyclin receptor agonist, $n$ (\%) & $7(70 \%)$ & $3(30 \%)$ & $6(60 \%)$ & NA & & \\
\hline Pulse (beats/min) & $80 \pm 8$ & $77 \pm 8$ & $77 \pm 7$ & 0.6 & $69 \pm 12$ & 0.04 \\
\hline Pulmonary vascular resistance (Wood units) & $10.3 \pm 4.6$ & $6.7 \pm 4.3$ & $7.5 \pm 4.8$ & 0.2 & & \\
\hline 6 minute walk distance $(\mathrm{m})$ & $446.1 \pm 82.9$ & $496.7 \pm 97.6$ & $440.7 \pm 158.9$ & 0.5 & NA & NA \\
\hline NT-proBNP (pg/ml) & $170(36,492)$ & $57(28,167)$ & $127(14,518)$ & 0.9 & $44(22,64)$ & 0.3 \\
\hline WHO functional class (I/II/III) & $1 / 6 / 3$ & $3 / 6 / 1$ & $1 / 7 / 2$ & 0.7 & NA & NA \\
\hline
\end{tabular}

Numerical variables are presented as mean \pm standard deviation, or alternatively as median (25th percentile, 75th percentile) when distributions are substantially skewed. A,BFisher's exact or $\chi^{2}$ for categorical values and ANOVA for quantitative values and in cases of skewed distributions; ANOVA was applied to log-transformed values. $P$ value ${ }^{A}$, comparing the 3 pulmonary hypertension study groups; $P$ value ${ }^{B}$, comparing the 3 study groups and controls. 'Historical data. NA, non-applicable; NT-proBNP, N-terminal pro-B-type natriuretic peptide.

most efficacious therapy in heart failure $(4,5)$. While $\beta$-blockade is an approved therapy in LV and global heart failure, its use in RV failure is not yet established (6). In fact, $\beta$-blockers are relatively contraindicated in PAH owing to concerns about possible negative effects on hemodynamics and exercise capacity in PAH patients. This is based on a small study of 10 patients with portopulmonary hypertension in whom withdrawal of the $\beta$-blocker propranolol was associated with improved exercise tolerance (7). Another case report described a single patient with portopulmonary hypertension treated with $\beta$-blocker for supraventricular tachycardia; treatment led to acute cardiovascular decompensation (8). In yet another study, patients with severe mitral stenosis and pulmonary hypertension $(\mathrm{PH})$ undergoing valvuloplasty had increased pulmonary vascular resistance and decreased cardiac output when given the $\beta$-blocker atenolol (9). 


\section{CONSORT}

TRANSPARENT REPORTING Of TRIALS

\section{CONSORT 2010 Flow Diagram}

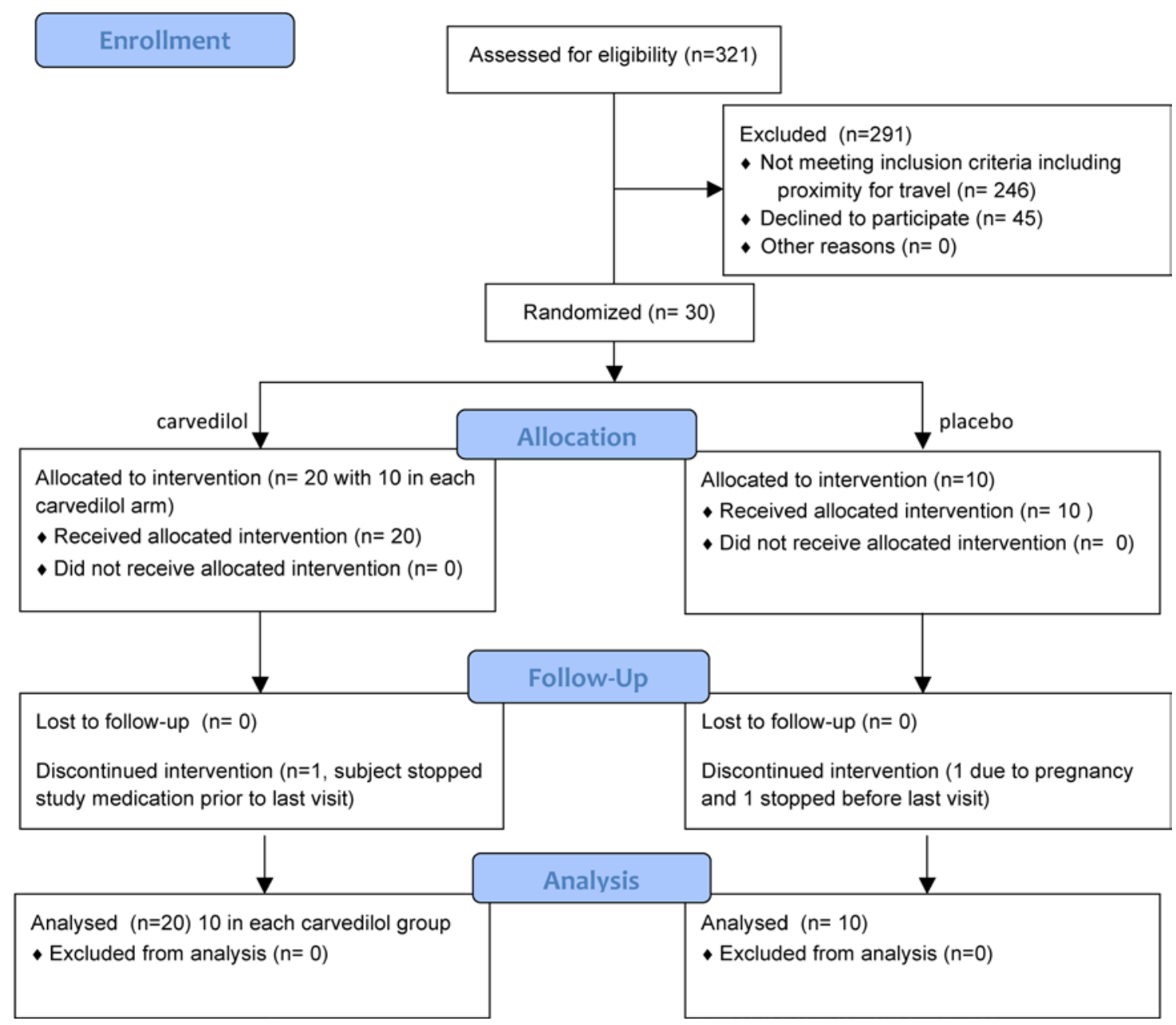

Figure 1. Consort Flow Chart.

Despite these anecdotal reports of adverse consequences, there is good reason to consider $\beta$-blocker therapy for the RV failure of PAH. Similar to left heart failure, the sympathetic nervous system and reninangiotensin-aldosterone system are overly activated (10-13). Markers of sympathetic overactivation in $\mathrm{PAH}$ are comparable to those found in LV failure (14). Likewise, similar to left heart failure, $\beta$ AR abnormalities are found in the RV of patients with PAH. Bristow et al. showed loss of $\beta_{1}$-ARs in the failing $\mathrm{RV}$, depletion of tissue norepinephrine, and lower levels of adenylate cyclase activity at baseline and in response to stimulation, which were identical to findings in left heart failure (13). Another study recently confirmed these findings through identification of lesser numbers of $\beta$ ARs in circulating mononuclear cells in individuals with PAH as compared with healthy controls or those with asthma (15).

Based on these concepts, recent studies have aimed to assess the safety of $\beta$-blockers in RV failure and the efficacy in preventing and/or reversing of right heart remodeling. $\beta$-Blockers improve RV function and 
prevent myocardial remodeling in animal models of $\mathrm{PH}(16,17)$. Clinical studies using $\beta$-blockers in $\mathrm{PAH}$ are limited and nonrandomized $(7-9,18-22)$, but some suggest safety and possible benefits of $\beta$-blockers, particularly carvedilol, a nonselective $\beta$-blocker with vasodilator properties (19). Nonselective $\beta$-blockers improve cardiac function and restore endothelial function, which make them particularly attractive for PAH treatment $(16,17)$. Here, the safety and possible benefits of the nonselective $\beta$-blocker/vasodilator carvedilol were evaluated in a 6-month double-blind, placebo-controlled, randomized trial in patients with PAH (Pulmonary Arterial Hypertension Treatment with Carvedilol for Heart failure [PAHTCH]). Outcomes included typical assessments of clinical functions as well as biochemical biomarkers associated with mechanisms underlying PAH, i.e., levels of $\beta A R$ and its signal transducer cyclic adenosine monophosphate (cAMP), levels of erythropoietin, and cardiac glucose uptake to assess pathologic hypoxia-inducible events.

\section{Results}

\section{Participants}

Individuals $(n=321)$ in a $\mathrm{PH}$ registry were reviewed for consideration of being approached for the study based on inclusion/exclusion criteria, and availability of individuals for frequent study visits and calls over 6 months. Thirty patients were consented and randomized, 10 in each study group (Figure 1). Baseline characteristics are summarized in Table 1 and detailed PAH-specific therapy in Supplemental Table 1; supplemental material available online with this article; https://doi.org/10.1172/jci.insight.95240DS1. Participants assigned to the dose-escalating carvedilol group were randomly older compared with the placebo group and the low-fixed-dose group (age [years]: dose-escalating group $53 \pm 9$; placebo group $38 \pm 14$; low-fixed-dose group $42 \pm 6 ; P=0.006$ ) (Table 1 ). A cohort of 12 healthy controls was enrolled in parallel for baseline comparison with the PH subjects. Baseline characteristics are shown in Table 1. Controls had similar age, height, gender, and race distribution as $\mathrm{PH}$ participants (Supplemental Table 2). Controls had lower weight compared with the $\mathrm{PH}$ participants $(P=0.002)$. As expected, the $\mathrm{PH}$ group had worse right atrial and ventricular functions as determined by echocardiography and elevated N-terminal pro-Btype natriuretic peptide (NT-proBNP) as compared with healthy controls (Supplemental Table 2). The PH group had higher heart rates, supportive of catecholamine overload. $\mathrm{PH}$ individuals also had higher glucose uptake as measured by 2 - $\left[{ }^{18} \mathrm{~F}\right]$ fluoro-2-deoxy-D-glucose (FDG) positron emission tomography (PET) in the right ventricle (23-25). These findings are in support of the well-recognized RV dysfunction and glycolytic shift with pathologic activation of hypoxia pathways in $\mathrm{PH}(23,24,26-29)$.

\section{Outcomes}

Safety and tolerability of carvedilol. All 30 participants tolerated the 1-week run-in low-dose carvedilol with no significant changes in heart rate (baseline, $78 \pm 7$; 1-week, $77 \pm 8 ; P=0.3$ ) and a slight decrease in systolic blood pressure (baseline, $119 \pm 17$; 1-week, $112 \pm 13 ; P=0.003$ ). Of the 30 enrolled participants, 29 completed the 6-month study. One participant exited the study at 4 months because of pregnancy. Five participants had dose de-escalation: 4 were in the dose-escalating carvedilol group (final dose $12.5 \mathrm{mg}$ [ $n=$ $3]$ and $3.125 \mathrm{mg}[n=1]$ ) and 1 in the low-fixed-dose carvedilol group (final dose $0 \mathrm{mg}$ ). Two participants stopped taking the study drug before their last visit ( 2 months and 3 months prior to last study visit); 1 in the placebo group and 1 in the carvedilol dose-escalating group. Fifteen adverse events were identified and reported to the IRB (Supplemental Table 3). Thus, although some participants required dose de-escalation due to minor adverse effects, carvedilol was safe and well tolerated throughout the study in all participants.

NT-proBNP levels were similar among the 3 groups at all study visits $(P>0.1)$ and did not change significantly over the time of the study in any of the study groups. This indicates that carvedilol therapy did not worsen heart failure.

Effects of carvedilol on heart rate, blood pressure, oxygen saturation, and temperature Heart rate decreased with carvedilol therapy (Table 2). Even after adjusting for age, the dose-escalating carvedilol group tended to have lower heart rates than the placebo group at the 1-month and 3-month visits $(P$ $=0.05$ and 0.07 , respectively). Heart rate correlated strongly with pill dosage (mg carvedilol) at the 1-month and 3-month visits $(R=-0.5, P=0.006$ and $R=-0.4, P=0.04$, respectively).

Systolic blood pressure tended to drop in the dose-escalating group at both the 1-month and 3-month visits (systolic blood pressure [mmHg]: baseline $122 \pm 17$; 1 -month visit $114 \pm 16[P=0.04]$; 3-month visit 
Table 2. Differences in clinical outcomes measured among the 3 study groups at baseline, 1-month, 3-month, and 6-month visits

\begin{tabular}{|c|c|c|c|c|}
\hline \multirow[b]{2}{*}{ Variable } & \multirow{2}{*}{$\begin{array}{l}\text { Placebo } \\
n=10\end{array}$} & \multicolumn{2}{|c|}{ Low-fixed-dose Carvedilol Escalating-dose Carvedilol } & \multirow{2}{*}{$\begin{array}{l}\text { ANOVA } \\
P \text { value }\end{array}$} \\
\hline & & $n=10$ & $n=10$ & \\
\hline \multicolumn{5}{|l|}{ Baseline } \\
\hline Weight (kg) & $78 \pm 15$ & $76 \pm 16$ & $93 \pm 23$ & 0.09 \\
\hline Temperature $\left({ }^{\circ} \mathrm{F}\right)$ & $97.6 \pm 0.5$ & $97.2 \pm 0.3$ & $97.3 \pm 0.9$ & 0.5 \\
\hline \multicolumn{5}{|l|}{ 6-minute walk test } \\
\hline Distance walked (m) & $404 \pm 84$ & $504 \pm 93$ & $438 \pm 158$ & 0.5 \\
\hline Oxygen saturation at $6 \mathrm{~min}(\%)$ & $88 \pm 6$ & $93 \pm 4$ & $89 \pm 6$ & 0.09 \\
\hline Heart rate at rest (beats/min) & $82 \pm 9$ & $78 \pm 5$ & $79 \pm 8$ & 0.5 \\
\hline Heart rate at 6 min (beats/min) & $111 \pm 17$ & $122 \pm 26$ & $122 \pm 13$ & 0.4 \\
\hline Heart rate 1 min after exercise (beats/min) & $97 \pm 14$ & $96 \pm 14$ & $100 \pm 17$ & 0.8 \\
\hline Heart rate recovery (beats/min) & $12 \pm 18$ & $26 \pm 19$ & $22 \pm 16$ & 0.2 \\
\hline NT-proBNP (pg/ml) & $170(37,492)$ & $57(28,167)$ & $127(14,518)$ & 0.9 \\
\hline \multicolumn{5}{|l|}{ Hematological parameters } \\
\hline $\mathrm{RBC}(\mathrm{m} / \mu \mathrm{l})$ & $4.7 \pm 0.4$ & $4.7 \pm 0.4$ & $4.8 \pm 0.7$ & 0.9 \\
\hline Hemoglobin (g/dl) & $13.7 \pm 1.7$ & $13.5 \pm 1.9$ & $13.5 \pm 2.3$ & 0.9 \\
\hline RDW (\%) & $14.9 \pm 2.5$ & $14.0 \pm 1.1$ & $15.0 \pm 1.2$ & 0.4 \\
\hline Platelets $(\mathrm{k} / \mu \mathrm{l})$ & $241 \pm 98$ & $229 \pm 76$ & $194 \pm 103$ & 0.5 \\
\hline \multicolumn{5}{|l|}{ At 1-month follow up } \\
\hline Weight $(\mathrm{kg})$ & $78 \pm 15$ & $76 \pm 16$ & $94 \pm 23$ & 0.07 \\
\hline Temperature $\left({ }^{\circ} \mathrm{F}\right)$ & $97.7 \pm 1.2$ & $97.3 \pm 0.8$ & $96.8 \pm 0.9$ & 0.1 \\
\hline NT-proBNP (pg/ml) & $183(68,370)$ & $92(69,208)$ & $120(74,639)$ & 0.9 \\
\hline \multicolumn{5}{|l|}{ At 3-month follow up } \\
\hline Weight $(\mathrm{kg})$ & $78 \pm 14$ & $76 \pm 17$ & $93 \pm 2$ & 0.08 \\
\hline Temperature $\left({ }^{\circ} \mathrm{F}\right)$ & $97.7 \pm 0.3$ & $97.2 \pm 0.3$ & $96.9 \pm 0.3$ & 0.2 \\
\hline \multicolumn{5}{|l|}{ 6-minute walk test } \\
\hline Distance walked (m) & $412 \pm 84$ & $504 \pm 93$ & $438 \pm 159$ & 0.2 \\
\hline Oxygen saturation at $6 \mathrm{~min}(\%)$ & $89 \pm 6$ & $93 \pm 6$ & $90 \pm 5$ & 0.2 \\
\hline Heart rate at rest (beats/min) & $78 \pm 10$ & $72 \pm 9$ & $68 \pm 10^{A}$ & 0.09 \\
\hline Heart rate at 6 min (beats/min) & $103 \pm 26$ & $124 \pm 26$ & $105 \pm 17^{A}$ & 0.1 \\
\hline Heart rate $1 \mathrm{~min}$ after exercise (beats/min) & $91 \pm 22$ & $88 \pm 10$ & $78 \pm 13^{A}$ & 0.2 \\
\hline Heart rate recovery (beats/min) & $12 \pm 22$ & $36 \pm 19$ & $27 \pm 15$ & 0.03 \\
\hline NT-proBNP $(p g / m l)$ & $152(41,487)$ & $79(36,138)$ & $169(50,467)$ & 0.8 \\
\hline \multicolumn{5}{|l|}{ At 6-month follow up } \\
\hline Weight $(\mathrm{kg})$ & $80 \pm 12$ & $77 \pm 17$ & $91 \pm 19$ & 0.1 \\
\hline Temperature ( $\left.{ }^{\circ} \mathrm{F}\right)$ & $97.6 \pm 0.4$ & $97.5 \pm 0.7$ & $97.2 \pm 1.1$ & 0.5 \\
\hline \multicolumn{5}{|l|}{ 6-minute walk test } \\
\hline Distance walked (m) & $453 \pm 60$ & $486 \pm 90$ & $450 \pm 180$ & 0.7 \\
\hline Oxygen saturation at $6 \min (\%)$ & $90 \pm 3$ & $91 \pm 7$ & $86 \pm 8$ & 0.3 \\
\hline Heart rate at rest (beats/min) & $73 \pm 10$ & $74 \pm 7^{\mathrm{A}}$ & $72 \pm 9^{A}$ & 0.8 \\
\hline Heart rate at 6 min (beats/min) & $116 \pm 35$ & $119 \pm 17$ & $111 \pm 20$ & 0.8 \\
\hline Heart rate $1 \mathrm{~min}$ after exercise (beats/min) & $93 \pm 24$ & $99 \pm 14$ & $82 \pm 16^{A}$ & 0.1 \\
\hline Heart rate recovery (beats/min) & $23 \pm 19$ & $20 \pm 44$ & $30 \pm 11$ & 0.5 \\
\hline NT-proBNP $(p g / m l)$ & $293(59,495)$ & $52(32,124)$ & $146(55,348)$ & 0.7 \\
\hline \multicolumn{5}{|l|}{ Hematological parameters } \\
\hline $\mathrm{RBC}(\mathrm{m} / \mu \mathrm{l})$ & $4.8 \pm 0.6$ & $4.5 \pm 0.5$ & $4.6 \pm 0.5$ & 0.7 \\
\hline Hemoglobin (g/dl) & $13.8 \pm 1.4$ & $13.0 \pm 2.3$ & $12.9 \pm 1.8$ & 0.6 \\
\hline RDW (\%) & $14.1 \pm 1.6$ & $14.4 \pm 1.5$ & $15.4 \pm 1.8$ & 0.3 \\
\hline Platelets $(\mathrm{k} / \mu \mathrm{l})$ & $208 \pm 86$ & $263 \pm 101$ & $156 \pm 71$ & 0.09 \\
\hline
\end{tabular}

Numerical variables are presented as mean \pm standard deviation, or alternatively as median (25th percentile, 75th percentile) when distributions are substantially skewed. ${ }^{A} P<0.025$; ${ }^{B} P<0.017$; paired $t$ test with Bonferroni-adjusted significance for change compared to baseline. ANOVA for comparison among all 3 groups at each time point and in cases of skewed distributions; ANOVA was applied to log-transformed values. NT-proBNP, $\mathrm{N}$-terminal pro-B-type natriuretic peptide; k, 1,000; RDW, RBC distribution width. 

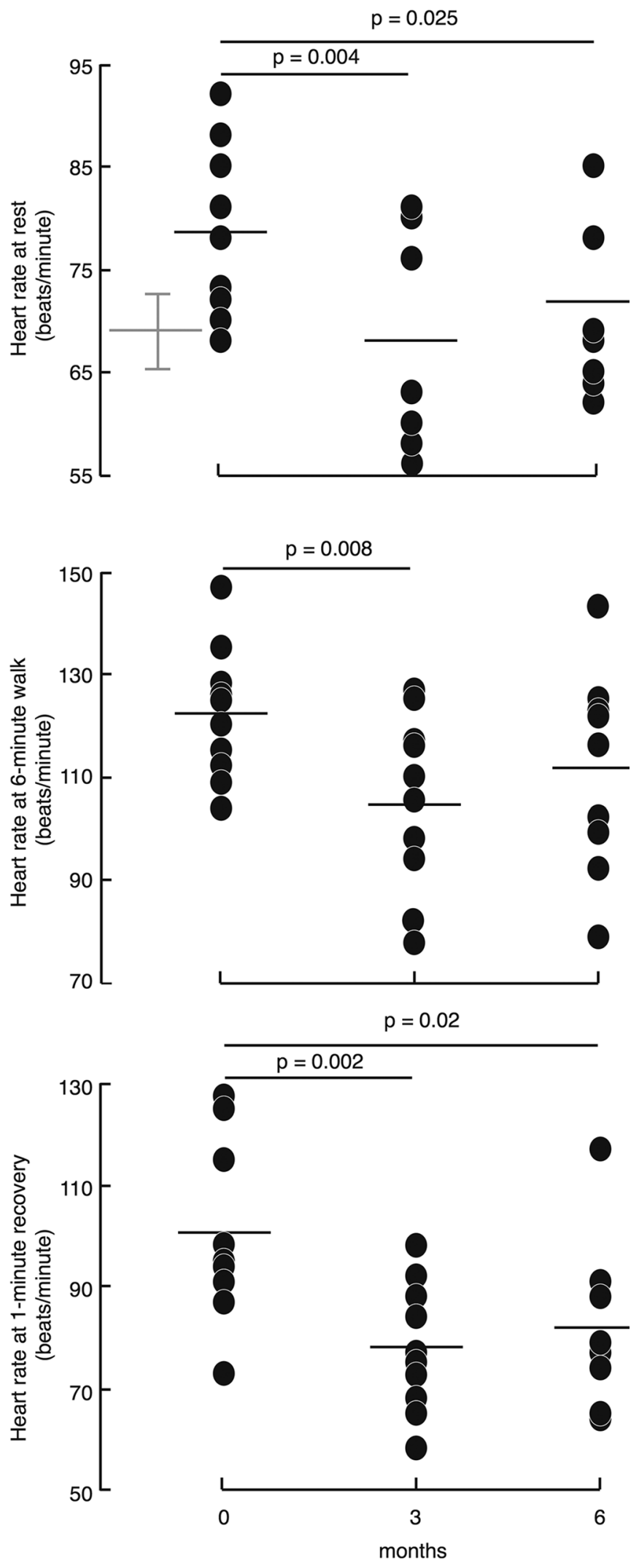

Figure 2. Heart rate reduction with dose-escalation carvedilol therapy. Carvedilol therapy reduced heart rate over the 6-month period in the doseescalating group ( $n=10$ at each time point). The effect was more pronounced at rest and during recovery at 1 minute after a 6 -minute walk test. The drop in heart rate was not accompanied by a worsening of functional capacity as measured by 6-minute walk distance (not shown in figure). Horizontal lines represent the mean. The gray lines represent control heart rate mean and SEM. Paired $t$ test with Bonferroni-adjusted significance level 0.025 used to adjust for comparisons to each of 3 and 6 months.

$112 \pm 19[P=0.08])$. Diastolic blood pressure dropped at the 1 -week and 3-month visits compared with baseline in the low-fixed-dose group (diastolic blood pressure $[\mathrm{mmHg}]$ : baseline $81 \pm 12$; 1-week visit $71 \pm 11[P=0.05]$; 3 -month visit $73 \pm 15[P=0.03]$ ).

Oxygen saturation did not vary over the course of the study among the different groups or within each individual study group (all $P>0.1$ ). There were no differences in temperature among the 3 study groups at baseline or at any of the study visits. Temperature did not change significantly within any of the study groups over time (all $P>0.1$ ). Similarly, weight did not vary over the course of the study among the different groups or within each individual study group (all $P>0.1$ ). The drops in heart rate and blood pressure with carvedilol therapy were well tolerated and did not lead to dose de-escalation.

\section{Pulmonary function during carvedilol therapy}

Spirometry and diffusing capacity of the lungs for carbon monoxide (DLCO) were measured at initial visit and at 3 and 6 months after randomization. Lung functions were similar among the groups at all visits (Table 3). However, within all study groups, airflow (forced expiratory volume during first second $\left[\mathrm{FEV}_{1}\right]$ ) decreased at the 3-month visit (change in $\mathrm{FEV}_{1}$ compared with baseline [L] at 3 months: placebo group $-0.08 \pm 0.1 ; P=0.02$; low-fixed-dose group $-0.09 \pm 0.14 ; P=0.06$; dose-escalating group $-0.17 \pm 0.14 ; P=0.005)$. $\mathrm{FEV}_{1} \%$ was $5 \%$ lower than baseline in the dose-escalating group at 3 months $(P=0.002) . \mathrm{FEV}_{1}$ and $\mathrm{FEV}_{1} \%$ decreased at the 6-month visit only in the low-dose group (change in $\mathrm{FEV}_{1}[\mathrm{~L}]:-0.17 \pm 0.16 ; P=0.009$ and $3 \%$ drop in $\mathrm{FEV}_{1} \%: 5 \pm 5 ; P=0.01$ ). Forced vital capacity (FVC) was not different among the 3 study groups over the different visits (all $P>$ 0.1 ). FVC and FVC\% dropped slightly at the 3-month visit in the dose-escalating group $(P<0.001)$. At the 6-month visit, FVC and FVC $\%$ decreased in the low-dose group $(P=0.03)$. The $\mathrm{FEV}_{1} /$ FVC ratio did not vary within the study groups over time (all $P>$ 0.1). DLCO and DLCO corrected for alveolar volume (DLCO/ VA) were similar among the 3 study groups at all visits (all $P>0.1$ ) (Table 3). Altogether, these findings show that carvedilol therapy did not substantially affect lung functions over a 6-month time period in PAH individuals. Clinical signs of airflow deterioration were not observed. The small but significant decreases in FVC and $\mathrm{FEV}_{1}$ did not require dose adjustment.

Six-minute walk test and heart rate recovery with carvedilol therapy

One of the main reasons for the relative contraindication of $\beta$-blockade in PAH is an observed decrease in functional capacity, such as 6-minute walk distance, with its use. Here, 6-minute walk was performed 
Table 3. Lung functions over course of PAHTCH

\begin{tabular}{|c|c|c|c|c|}
\hline Variable & $\begin{array}{c}\text { Placebo } \\
n=10\end{array}$ & $\begin{array}{l}\text { Low-fixed-dose Carvedilol } \\
\qquad n=10\end{array}$ & $\begin{array}{l}\text { Escalating-dose Carvedilol } \\
\qquad n=10\end{array}$ & $\begin{array}{l}\text { ANOVA } \\
P \text { value }\end{array}$ \\
\hline \multicolumn{5}{|l|}{ Baseline } \\
\hline FVC & $3.2 \pm 0.9$ & $3.5 \pm 1.3$ & $3.2 \pm 0.9$ & 0.8 \\
\hline$\% F V C$ & $83 \pm 11$ & $89 \pm 16$ & $79 \pm 13$ & 0.2 \\
\hline $\mathrm{FEV}_{1}$ & $2.5 \pm 0.7$ & $2.7 \pm 0.9$ & $2.4 \pm 0.7$ & 0.7 \\
\hline$\% \mathrm{FEV}_{1}$ & $80 \pm 13$ & $86 \pm 16$ & $75 \pm 11$ & 0.2 \\
\hline \multicolumn{5}{|c|}{ At 3-month follow up } \\
\hline FVC & $3.1 \pm 1.1$ & $3.4 \pm 1.3$ & $3.1 \pm 0.8^{A}$ & 0.8 \\
\hline$\% F V C$ & $83 \pm 13$ & $86 \pm 16$ & $77 \pm 11^{A}$ & 0.3 \\
\hline $\mathrm{FEV}_{1}$ & $2.4 \pm 0.8^{A}$ & $2.6 \pm 0.9$ & $2.3 \pm 0.6^{A}$ & 0.7 \\
\hline$\% \mathrm{FEV}_{1}$ & $78 \pm 14$ & $83 \pm 16$ & $72 \pm 8^{A}$ & 0.2 \\
\hline$\% F V C$ & $83 \pm 15$ & $85 \pm 17$ & $76 \pm 8$ & 0.4 \\
\hline $\mathrm{FEV}_{1}$ & $2.5 \pm 0.8$ & $2.5 \pm 0.9^{A}$ & $2.3 \pm 0.6$ & 0.8 \\
\hline$\% \mathrm{FEV}_{1}$ & $79 \pm 15$ & $80 \pm 17^{A}$ & $73 \pm 7$ & 0.5 \\
\hline $\mathrm{FEV}_{1} / \mathrm{FVC}$ & $77 \pm 8$ & $77 \pm 7$ & $76 \pm 8$ & 0.9 \\
\hline DLCO & $27 \pm 11$ & $23 \pm 13$ & $23 \pm 8$ & 0.6 \\
\hline
\end{tabular}

Variables are presented as mean \pm standard deviation. ${ }^{A} P<0.025$; paired $t$ test with Bonferroni-adjusted significance for change compared to baseline. ANOVA for comparison among all 3 groups at each time point. PAHTCH, Pulmonary Arterial Hypertension Treatment with Carvedilol for Heart failure trial; FVC, forced vital capacity; FEV, forced expiratory volume during first second; DLCO, diffusing capacity of the lungs for carbon monoxide.

at baseline, after the 1-week run-in visit, and at the 3-month and 6-month visits. There were no significant differences in the distance walked among the 3 groups at any visit (all $P>0.1$ ). The changes in the distance walked over time were not different among the study groups, and there were no significant changes in distance walked within any of the groups (all $P>0.1$ ) (Table 2). Oxygen saturation during the walk was similar among the groups at all visits without significant changes within the groups (all $P>0.1$ ) (Table 2).

On the other hand, heart rates at peak exercise ( 6 minute) and 1 minute after exercise were lower in the carvedilol dose-escalating group. Heart rate at rest was lower in the dose-escalating carvedilol group at the 3-month and 6-month visits (Figure 2). After 3 months of carvedilol, the maximal heart rate at the end of the 6-minute walk was lower in the dose-escalating group (heart rate at 6-minute walk [beats/min]: baseline $122 \pm 13$; 3-month visit $105 \pm 17 ; P=0.008$ ) (Table 2 ). Heart rate at 1 minute after the walk was lower in the dose-escalating group at the 3-month and 6-month visits (heart rate at 1 minute after walk [beats/min]: baseline $100 \pm 17$; 3 -month visit $78 \pm 13 ; P=0.002 ; 6$-month visit $8216 ; P=0.02$ ) (Table 2$)$. The change in heart rate at 1 minute after walk correlated with carvedilol dose at the 3 -month visit $(R=-0.4, P=0.03)$.

Heart rate recovery was faster in the low-fixed-dose compared with the placebo group at the 3-month visit (heart rate recovery [beats/min]: placebo group $12 \pm 23$; low-fixed-dose group $36 \pm 19$; dose-escalating group $27 \pm 15 ; P=0.03)$. This difference remained significant after adjusting for age $(P=0.01)$. Heart rate recovery tended to be faster in the dose-escalating carvedilol group at the 6-month visit compared with baseline (heart rate recovery [beats/min]: baseline $22 \pm 16$; 6-month visit $30 \pm 11 ; P=0.06$ ). Overall, carvedilol therapy reduced heart rate at rest and at 1 -minute postwalk recovery more than at peak exercise. The reduction in heart rate did not affect exercise capacity as measured by 6-minute walk distance.

\section{Cambridge Pulmonary Hypertension Outcome Review (CAMPHOR)}

The CAMPHOR questionnaire is a PH-specific measure and is made up of 3 main scales that assess symptoms, functioning, and quality of life $(30,31)$. The symptom dimension is made up of 25 symptoms divided into 3 subscales: energy, breathlessness, and mood. The activity scale has 15 items. The qualityof-life scale has 25 items, with focus on socialization, role, acceptance, self-esteem, independence, 
Table 4. Differences in echocardiographic measurements among the three study groups at baseline, 3-month, and 6-month visits

\begin{tabular}{|c|c|c|c|c|}
\hline Variable & $\begin{array}{c}\text { Placebo } \\
n=10\end{array}$ & $\begin{array}{l}\text { Low-fixed-dose Carvedilol } \\
\qquad n=10\end{array}$ & $\begin{array}{l}\text { Escalating-dose Carvedilol } \\
\qquad n=10\end{array}$ & $\begin{array}{l}\text { ANOVA } \\
P \text { value }\end{array}$ \\
\hline \multicolumn{5}{|l|}{ Baseline } \\
\hline \multicolumn{5}{|l|}{ Echocardiogram } \\
\hline LA area $\left(\mathrm{cm}^{2}\right)$ & $17 \pm 2$ & $17 \pm 3$ & $19 \pm 4$ & 0.4 \\
\hline LVEDD (cm) & $4.4 \pm 0.7$ & $4.5 \pm 0.7$ & $4.5 \pm 0.7$ & 0.8 \\
\hline LVESD (cm) & $2.5 \pm 0.5$ & $2.6 \pm 0.8$ & $2.8 \pm 0.9$ & 0.8 \\
\hline $\mathrm{RAP}(\mathrm{mmHg})$ & $6 \pm 2$ & $7 \pm 3$ & $8 \pm 5$ & 0.5 \\
\hline RVED area $\left(\mathrm{cm}^{2}\right)$ & $31 \pm 6$ & $26 \pm 4$ & $30 \pm 13$ & 0.4 \\
\hline RVES area $\left(\mathrm{cm}^{2}\right)$ & $23 \pm 7$ & $18 \pm 5$ & $22 \pm 12$ & 0.4 \\
\hline RVSP (mmHg) & $76 \pm 22$ & $63 \pm 28$ & $63 \pm 31$ & 0.5 \\
\hline RVFAC (\%) & $27 \pm 11$ & $32 \pm 10$ & $29 \pm 10$ & 0.5 \\
\hline \multicolumn{5}{|l|}{ At 3-month follow up } \\
\hline \multicolumn{5}{|l|}{ Echocardiogram } \\
\hline LA area $\left(\mathrm{cm}^{2}\right)$ & $16 \pm 2$ & $16 \pm 4$ & $20 \pm 5$ & 0.03 \\
\hline LVEDD (cm) & $4.3 \pm 0.8$ & $4.6 \pm 0.6$ & $4.7 \pm 0.8$ & 0.5 \\
\hline $\operatorname{LVESD}(\mathrm{cm})$ & $2.5 \pm 0.9$ & $2.8 \pm 0.7$ & $2.8 \pm 0.7$ & 0.5 \\
\hline LVEF (\%) & $61 \pm 5$ & $64 \pm 5$ & $62 \pm 7$ & 0.6 \\
\hline $\mathrm{RA}$ area $\left(\mathrm{cm}^{2}\right)$ & $17 \pm 5$ & $20 \pm 8$ & $21 \pm 6$ & 0.3 \\
\hline $\mathrm{RAP}(\mathrm{mmHg})$ & $5 \pm 0$ & $7 \pm 2$ & $9 \pm 5$ & 0.08 \\
\hline RVED area $\left(\mathrm{cm}^{2}\right)$ & $29 \pm 7$ & $27 \pm 8$ & $31 \pm 9$ & 0.5 \\
\hline RVES area $\left(\mathrm{cm}^{2}\right)$ & $24 \pm 7$ & $19 \pm 8$ & $22 \pm 8$ & 0.4 \\
\hline RVSP (mmHg) & $78 \pm 21$ & $59 \pm 18$ & $54 \pm 24$ & 0.05 \\
\hline LA area $\left(\mathrm{cm}^{2}\right)$ & $17 \pm 3$ & $17 \pm 3$ & $20 \pm 3$ & 0.03 \\
\hline LVEDD (cm) & $4.4 \pm 0.6$ & $4.6 \pm 0.7$ & $4.9 \pm 0.6$ & 0.3 \\
\hline LVESD (cm) & $2.8 \pm 0.5$ & $2.8 \pm 0.6$ & $2.7 \pm 0.6$ & 0.9 \\
\hline LVEF (\%) & $58 \pm 6$ & $60 \pm 7$ & $63 \pm 6$ & 0.4 \\
\hline $\mathrm{RA}$ area $\left(\mathrm{cm}^{2}\right)$ & $19 \pm 4$ & $21 \pm 9$ & $21 \pm 6$ & 0.7 \\
\hline $\mathrm{RAP}(\mathrm{mmHg})$ & $6 \pm 2$ & $6 \pm 2$ & $8 \pm 4$ & 0.2 \\
\hline RVED area $\left(\mathrm{cm}^{2}\right)$ & $31 \pm 6$ & $28 \pm 11$ & $34 \pm 13$ & 0.4 \\
\hline RVES area $\left(\mathrm{cm}^{2}\right)$ & $23 \pm 5$ & $20 \pm 10$ & $23 \pm 9$ & 0.6 \\
\hline RVSP (mmHg) & $66 \pm 23$ & $51 \pm 22$ & $64 \pm 32$ & 0.4 \\
\hline RVFAC (\%) & $25 \pm 9$ & $30 \pm 10$ & $27 \pm 11$ & 0.6 \\
\hline $\operatorname{LV} S V(m l)$ & $63 \pm 12$ & $68 \pm 21$ & $70 \pm 19$ & 0.7 \\
\hline LV cardiac output (I/min) & $4.5 \pm 0.9$ & $4.7 \pm 1.6$ & $4.9 \pm 1.7$ & 0.8 \\
\hline RV peak global longitudinal strain (\%) & $-15 \pm 4$ & $-18 \pm 4$ & $-17 \pm 4$ & 0.3 \\
\hline LV peak global longitudinal strain (\%) & $-14 \pm 12$ & $-17 \pm 3$ & $-19 \pm 3$ & 0.3 \\
\hline
\end{tabular}

Numerical variables are presented as mean \pm standard deviation. ${ }^{A} P<0.025$; paired $t$ test with Bonferroni-adjusted significance for change compared with baseline. ANOVA for comparison among all 3 groups at each time point. LA, left atrial; LV, left ventricular; LVEDD, LV end-diastolic diameter; LVESD, LV end-systolic diameter; LVEF, LV ejection fraction; RA, right atrial; RAP, RA pressure; RV, right ventricular; RVED, RV end diastolic; RVES, RV end-systolic; RVSP, RV systolic pressure; RVFAC, RV fractional area change; SV, stroke volume. 


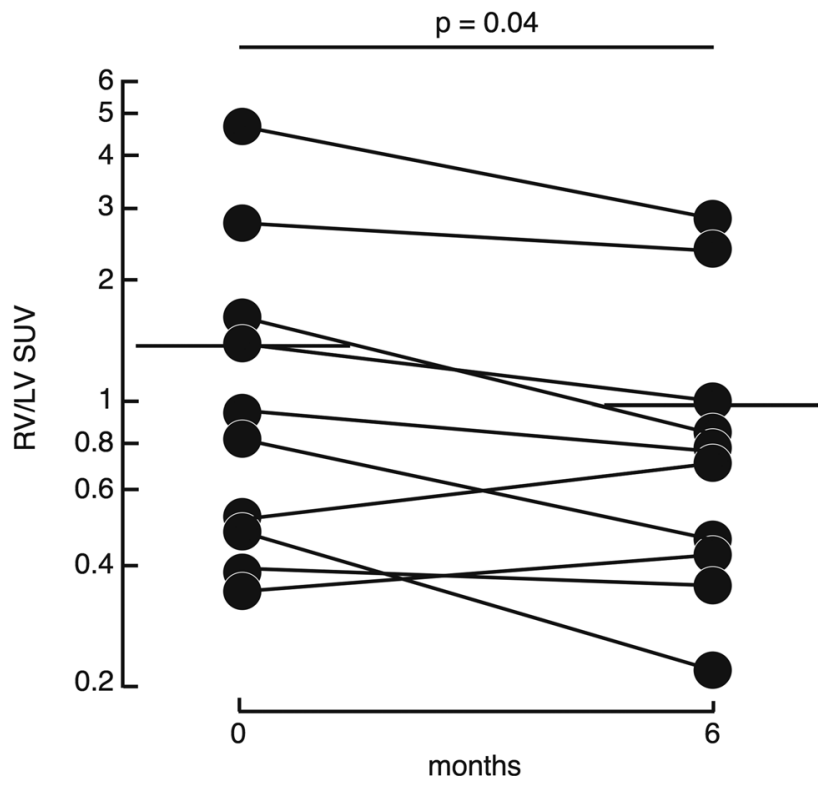

Figure 3. Right ventricle (RV) uptake of 2-[ $\left.{ }^{18} \mathrm{~F}\right]$ fluoro-2-deoxy-D-glucose (FDG) relative to left ventricle (LV) with dose-escalating carvedilol. Individuals treated with dose-escalating carvedilol had a reduction in RV FDG uptake as measured by the ratio of RV to LV standardized uptake values (RV/LV SUV). $n=10$ at each time point; paired $t$-test analysis using log-transformed values. Horizontal lines represent means. Values of SUV are shown plotted on a logarithmic $y$ axis.

and security. Scores for quality of life and symptoms range from $0-25$, with higher scores indicating worse quality of life. Activity scores range from $0-30$, with higher scores indicating greater physical limitation. CAMPHOR was completed at baseline, after the 1-week run-in, 3-month, and 6-month visits. There were no significant differences in the scores among the groups at any visit. There was a small but significant drop in CAMPHOR score in the low-fixed-dose and placebo groups at the 6-month visit (both $P=0.04$ ). Thus, carvedilol therapy did not adversely affect CAMPHOR scores over a 6-month time period in $\mathrm{PH}$ individuals.

\section{Echocardiographic assessment of cardiovascular function}

Echocardiography was performed at baseline and at the 3-month and 6-month visits. The LV parameters, including LV end-diastolic diameter, LV end-systolic diameter, and LV ejection fraction, were similar among the study groups and did not vary over time (Table 4). Left atrial area was greater in the dose-escalating group compared with other groups at the 3-month and 6-month visits but did not significantly change within any of the groups over the course of the study (Table 4). Right atrial pressure did not change within groups over the time of the study. Other parameters of RV function and size, including RV end-diastolic diameter and RV end-systolic diameter, RV Tei, and tricuspid annular plane systolic excursion (TAPSE), did not change significantly over the time of the study within groups. However, RV systolic pressure (RVSP) at the 3-month visit tended to be higher in the placebo group as compared with carvedilol groups (RVSP [mmHg]: placebo group $78 \pm 21 ; P=0.02$; low-fixed-dose group $59 \pm 18 ; P=$ 0.06 ; dose-escalating group $54 \pm 24 ; P=0.05$ ) (Table 4). RVSP inversely correlated with carvedilol pill dose at 3 months $(R=-0.4 ; P=0.01)$. RV fractional area change (RVFAC) was higher at the 3-month visit in the dose-escalating group and the low-fixed-dose group compared with placebo (Table 4). RV global strain was not different among the study groups (Table 4). Stroke volume tended to increase at the 3-month and 6-month visits compared with baseline in the dose-escalating group (change in stroke volume compared with baseline: 3 -month visit $13 \pm 16 ; P=0.03$ and 6-month visit $12 \pm 19 ; P=0.08$ ) (Table 4). Cardiac output (LV CO) was not different among the 3 study groups at any visit and did not vary significantly within any of the study groups over the course of the study (all $P>0.1$ ) (Table 4). Altogether, carvedilol therapy was not associated with deterioration in cardiac parameters measured by echocardiography. In fact, RV function improved in the dose-escalating group in parallel with an increase in LV stroke volume. These changes could be a reflection of carvedilol direct effect on the RV or on afterload reduction or even a compensatory mechanism to maintain $\mathrm{CO}$ in the face of a reduction in heart rate.

\section{Assessment of hypoxia signaling: cardiac glucose uptake by PET scan and erythropoietin level}

Erythropoietin was measured at baseline and 1-month, 3-month, and 6-month visits. Erythropoietin levels were similar among the PH study groups and did not vary over the time of the study (all $P>0.1$ ).

FDG-PET scan was performed at baseline and at the 6-month visit. LV, RV, and septum FDG uptake were measured as maximal standardized uptake values (SUVs) in the LV and RV free walls and septal wall in images acquired 90 minutes after injection in the fasting state. The LV FDG uptakes were similar among study groups and did not change over the course of the study. The RV/LV FDG-uptake ratio was used to assess relative differences in RV FDG uptake among groups and among individuals over time. RV/LV FDG uptake was not different among the groups at baseline or at the 6-month follow up visit (both $P>0.1$ ). However, RV/LV FDG uptake decreased in the dose-escalating carvedilol group at the 6-month visit (RV/LV FDG uptake median $[25 \%, 75 \%]$ : baseline $0.9(0.5,1.5), 6$-month visit $0.7(0.4,1.0)$; log-transformed values: baseline $-0.2(-1.0,0.6), 6$-month visit 
Table 5. Differences in biological outcomes measured among the 3 study groups at baseline, 1-month, 3-month, and 6-month visits

\begin{tabular}{|c|c|c|c|c|}
\hline Variable & $\begin{array}{c}\text { Placebo } \\
n=10\end{array}$ & $\begin{array}{l}\text { Low-fixed-dose Carvedilol } \\
\qquad n=10\end{array}$ & $\begin{array}{l}\text { Escalating-dose Carvedilol } \\
\qquad n=10\end{array}$ & $\begin{array}{l}\text { ANOVA } \\
P \text { value }\end{array}$ \\
\hline \multicolumn{5}{|l|}{ Baseline } \\
\hline Hypoxia-Inducible Pathways & & & & \\
\hline Erythropoietin $(\mathrm{mlU} / \mathrm{ml})$ & $9.5(5.9,13.1)$ & $6.4(3.9,11.6)$ & $6.4(4.9,8.0)$ & 0.6 \\
\hline \multicolumn{5}{|l|}{ Heart glucose uptake by FDG-PET scan } \\
\hline RV/LV ratio (SUV) & $1.0(0.6,1.4)$ & $0.6(0.5,0.9)$ & $0.9(0.5,1.5)$ & 0.7 \\
\hline Urinary cAMP/creatinine $(\mu \mathrm{mol} / \mathrm{g})$ & $1.4(1.1,1.7)$ & $0.6(0.4,0.9)$ & $1.0(0.6,1.1)$ & 0.01 \\
\hline \multicolumn{5}{|l|}{ At 1-month follow up } \\
\hline \multicolumn{5}{|l|}{ Hypoxia-Inducible Pathways } \\
\hline Erythropoietin & $8.9(7.2,9.9)$ & $7.5(6.5,14.1)$ & $5.2(4.6,9.0)$ & 0.4 \\
\hline \multicolumn{5}{|l|}{ At 3-month follow up } \\
\hline \multicolumn{5}{|l|}{ Hypoxia-Inducible Pathways } \\
\hline Erythropoietin (mlU/ml) & $6.6(3.5,10.0)$ & $6.7(3.8,11.3)$ & $5.8(1.1,8.9)$ & 0.5 \\
\hline \multicolumn{5}{|l|}{$\beta$-Adrenergic Receptor } \\
\hline Urinary cAMP/creatinine ( $\mu \mathrm{mol} / \mathrm{g}$ ) & $1.2(0.8,1.8)$ & $0.6(0.5,1.0)$ & $1.5(0.6,1.7)$ & 0.3 \\
\hline \multicolumn{5}{|l|}{ At 6-month follow up } \\
\hline \multicolumn{5}{|l|}{ Hypoxia-Inducible Pathways } \\
\hline Erythropoietin & $11.0(3.6,13.4)$ & $9.8(5.7,12.2)$ & $4.2(2.6,12.0)$ & 0.5 \\
\hline \multicolumn{5}{|l|}{ Heart glucose uptake by FDG-PET scan } \\
\hline RV/LV ratio (SUV) & $0.8(0.7,1.1)$ & $0.6(0.4,0.8)$ & $0.7(0.4,1.0)^{A}$ & 0.7 \\
\hline \multicolumn{5}{|l|}{$\beta$-Adrenergic Receptor } \\
\hline
\end{tabular}

Numerical variables are presented as mean \pm standard deviation, or alternatively as median (25th percentile, 75th percentile) when distributions are substantially skewed. ${ }^{A} P=0.04$; ANOVA for comparison among all 3 groups at each time point and in cases of skewed distributions; ANOVA was applied to log-transformed values. RV, right ventricular; LV, left ventricular; SUV, standard uptake value; FDC, 2-[18F]fluoro-2-deoxy-D-glucose.

$-0.5(-1.2,-0.08)$; paired $t$ test $P=0.04)$ (Figure 3 and Table 5). RV/LV FDG uptake correlated with heart rate at 1 minute after the 6-minute walk $(R=0.4 ; P=0.03)$ and with $\operatorname{RVSP}(R=0.5 ; P=0.002)$ at 6-month visit (Figure 4). The baseline RV/LV FDG uptake correlated to echocardiographic measurements at baseline as recently published (24). The relationship of FDG uptake with heart rate, a correlate of the $\beta$-blocker efficaciousness, suggests the decrease in glucose uptake is related to carvedilol therapy. Overall, carvedilol therapy over a 6-month period led to reduced RV/LV uptake of glucose, suggesting that carvedilol improved RV function.

\section{$\beta A R$ expression}

Flow cytometry with alprenolol binding was used to quantify $\beta A R$ density on circulating white blood cells. $\beta A R$ density was similar among groups at baseline and 6 months (Table 5). However, the change in $\beta A R$ density relative to baseline was dose-dependently related to the carvedilol dose $(0 \mathrm{mg},-0.11 \pm 0.26 ; 3.125$ mg, $0.004 \pm 0.237 ; 12.5 \mathrm{mg}, 0.025 \pm 0.198 ; 25 \mathrm{mg}, 0.110 \pm 0.250 ; R=0.3 ; P=0.02$ ) (Figure 5). The greatest increase in $\beta$ AR density was found in those individuals on the highest dose of carvedilol $(P=0.02)$.

\section{Urinary CAMP}

$\beta A R$ activation in cardiac muscles is associated with increased cAMP as downstream signaling. Urinary cAMP/creatinine is a measure of $\beta A R$ function (32), and was used to assess $\beta A R$ recovery with carvedilol. Urinary cAMP/creatinine was highest in the placebo group at baseline but did not change over 

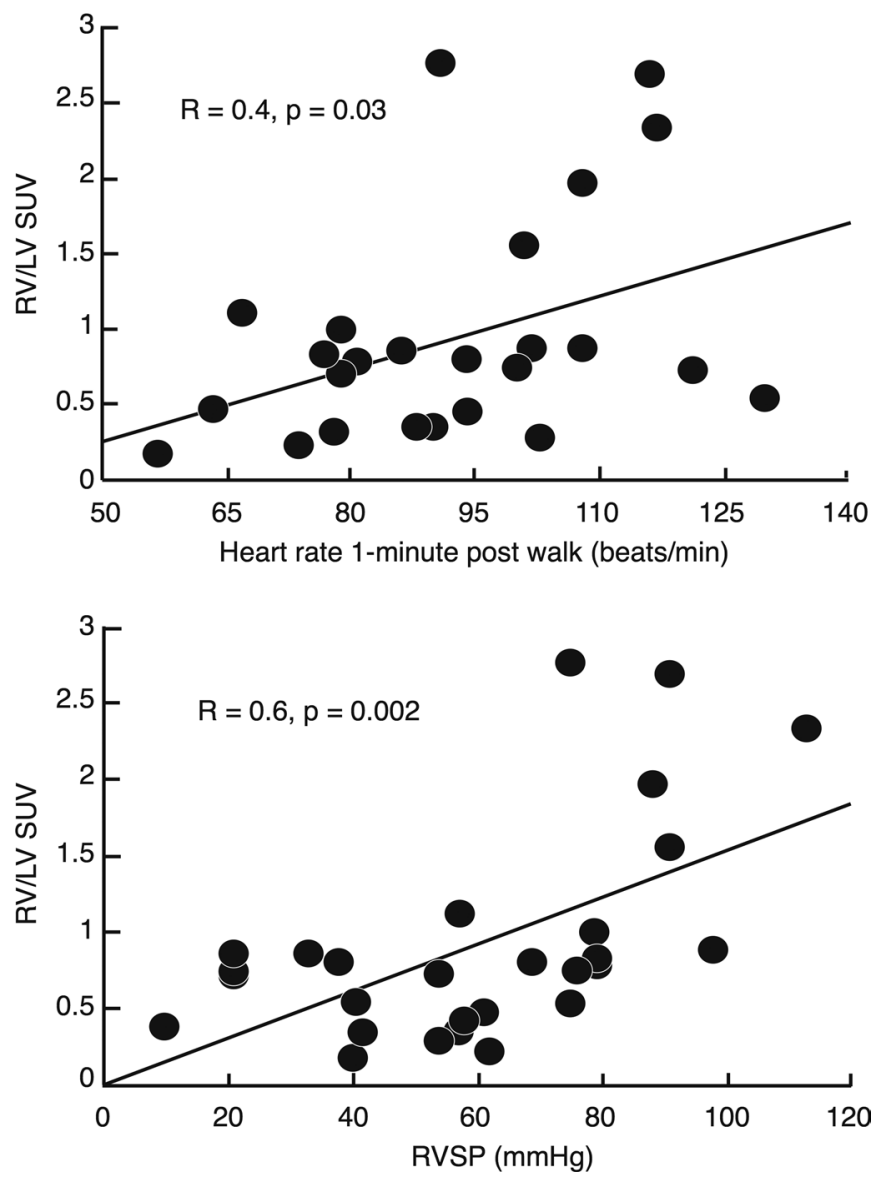

Figure 4. Association of RV/LV glucose uptake to heart rate and RV systolic pressure (RVSP). The ratio of right ventricular to left ventricular FDGuptake (RV/LV SUV) was associated with heart rate at 1-minute recovery after a 6-minute walk, and RVSP. Pearson correlations are based on values at the 6-month visit and include all participants $(n=30)$.

time in the placebo group (Table 5). In contrast, urinary cAMP/ creatinine tended to increase in the low-fixed-dose carvedilol group $(P=0.07)$ and the dose-escalating carvedilol group over time $(P=$ 0.04) (Figure 6).

\section{Carvedilol effects compared with placebo based on heart} rate

To further evaluate the effect of carvedilol, all participants receiving carvedilol, either low-fixed-dose or dose-escalating, were compared with those participants receiving placebo. At 3-month visit, heart rate at rest was lower in the carvedilol group compared with placebo (heart rate [beats/min]: placebo group $78 \pm 10$, carvedilol group $70 \pm 10 ; P=0.04)$. Heart rate at the end of walk at 6 minutes was similar among the 2 groups $(P=0.3)$, but heart rate at 1 minute after walk decreased at the 3-month visit in the treatment group (heart rate 1 minute after walk: baseline $98 \pm 16$, 3-month visit 83 $\pm 12 ; P<0.001$ ), but not in the placebo group (heart rate 1 minute after walk: baseline $97 \pm 14$, 3-month visit $91 \pm 22 ; P=0.2$ ). Heart rate recovery was fastest in the carvedilol group at the 3-month visit $(P=0.05)$ and significantly faster than in the placebo group (heart rate recovery [beats/min]: carvedilol group $32 \pm 17$, placebo group $12 \pm 22 ; P=0.01)$. At the 6 -month visit, heart rate differences could not be appreciated (all $P>0.1$ ).

Next, to adjust for dose de-escalation, variable adherence, and/or drop out, heart rate at rest was used as a physiologic surrogate of carvedilol effect among the population at 6 months. Heart rate correlated with parameters of right heart dysfunction by echocardiography, including with RVSP $(R=0.5 ; P<0.001)$ and inversely with RVFAC $(R=0.5 ; P<0.001)$. Heart rate correlated with cardiac RV/LV FDG uptake $(R=$ $0.4 ; P=0.002)$. These findings suggest that higher heart rates are associated with disease severity and dosing of carvedilol to achieve heart rate reductions may be of benefit to PAH. However, as the increased heart rate in this population is presumably a compensation for reduced stroke volume, introducing carvedilol should be performed under close observation to monitor for any decompensation.

\section{Changes in heart rate and RV metabolism excluding non-group $1 \mathrm{PAH}$}

The study cohort included 4 non-group $1 \mathrm{PH}$ patients. To evaluate if non-group $1 \mathrm{PAH}$ patient data influenced the findings, the data were also analyzed after excluding the 4 non-group 1 subjects. Similar to the entire cohort, dose-escalating carvedilol therapy decreased heart rate at rest $(P=0.007)$ and 1 minute after recovery $(P=0.01)$ without affecting heart rate at the end of the walk at 6 minutes $(P=0.1)$. Similarly, RV glucose uptake decreased in the dose-escalating group 1 patients at 6-month visit compared with baseline (RV/LV FDG uptake median [25\%, 75\%]: baseline 0.9 [0.5, 1.5], 6-month visit $0.7[0.4,1.0]$; log-transformed values: baseline $-0.2[-1.0,0.6], 6$-month visit $-0.5[-1.2,-0.08]$; paired $t$ test $P=0.01$ ). There were no significant changes in NT-proBNP or 6-minute walk distance over the time of the study in group $1 \mathrm{PAH}$ patients participating in any of the study arms (all $P>0.05$ ).

The findings support the effect of carvedilol on cardiac metabolism and heart rate in RV dysfunction regardless of the $\mathrm{PH}$ group.

\section{Discussion}

The PAHTCH trial reveals that carvedilol is safe and has potential benefits over 6 months for individuals with $\mathrm{PAH}$. Carvedilol was well tolerated, as evidenced by low numbers of adverse events requiring dose reductions. 


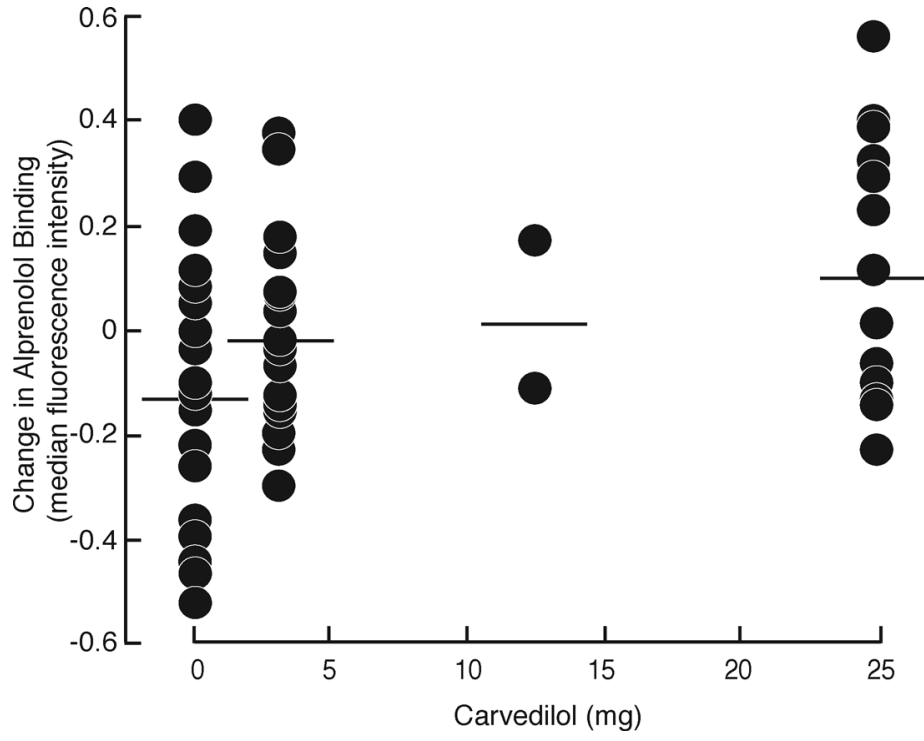

Figure 5. Carvedilol therapy recovers $\beta$-adrenergic receptor density as determined by alprenolol binding. Carvedilol dose was correlated with an increase in $\beta$-adrenergic receptor density relative to baseline levels (Pearson $P=0.02 ; n=53$ ).

Carvedilol lowered heart rate and accelerated heart rate recovery from exercise, but did not decrease exercise capacity. Carvedilol decreased RV glycolytic rate, and had no evidence of RV functional deterioration; rather, RV improvements were seen and cardiac output was maintained. The beneficial effects were associated with recovery of $\beta A R$ as measured by receptor density.

This double-blinded randomized study provides new data that advance our knowledge of $\beta$-blocker use in PAH. Nevertheless, previous studies supported the concept for this study. In a small single-arm study, $\beta$-blocker use in patients after correction of transposition of the great arteries showed improvement in symptoms, quality of life, and RV ejection fraction (22). In a prospective open-label study involving 94 patients with $\mathrm{PAH}$, So et al. showed that, in the $28 \%$ of patients who were prescribed a

variety of $\beta$-blockers, there were no greater adverse clinical or hemodynamic consequences associated with the administration of those drugs (21). The study had limitations in that it was nonrandomized, and there were differences in PAH subtypes, exercise capacity, and accompanying diseases between groups treated with and without $\beta$-blockers. In another small pilot study, Grinnan et al. evaluated carvedilol in patients with stable PAH and RV dysfunction (functional classes II and III) using cardiac magnetic resonance to measure interval changes in RV dimensions and systolic function (19). They showed that carvedilol was safe, and that there was an improvement in RV ejection fraction (19). In another small study, bisoprolol was well tolerated in patients with $\mathrm{PAH}$, but without appreciable benefits; there was a possible decrease in cardiac index and 6-minute walk distance (20). In retrospective analysis using propensity score matching, $\beta$-blocker use in patients with $\mathrm{PAH}$ was associated with similar survival and time to clinical worsening as compared with patients not receiving them (18). To the best of our knowledge this study is the first double-blinded, randomized, controlled trial using carvedilol at varying doses. Consistent with other studies, carvedilol was safe and tolerated, but unlike the bisoprolol study, there were no adverse functional effects. Further work is needed to determine the ideal class of $\beta$-blocker.

Although $\beta$ AR antagonists provide survival benefits in left heart failure, the benefits are also not consistent among the different $\beta$-blocker classes. Three different classes of $\beta$-blockers have been tried in left heart

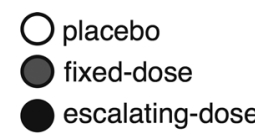

Figure 6. Carvedilol therapy recovers $\beta$-adrenergic receptor function as determined by change in urinary cAMP/creatinine. Carvedilol treated groups had a tendency to increase urinary cAMP/creatinine relative to baseline, though not statistically significant when corrected for multiple comparisons $\left({ }^{*} P=0.07\right.$ for the lowfixed-dose carvedilol group, and ${ }^{*} P=0.04$ for the dose-escalating carvedilol group; Bonferroniadjusted significance level required $P<0.017 ; n=$ 10 in each group at each time point).

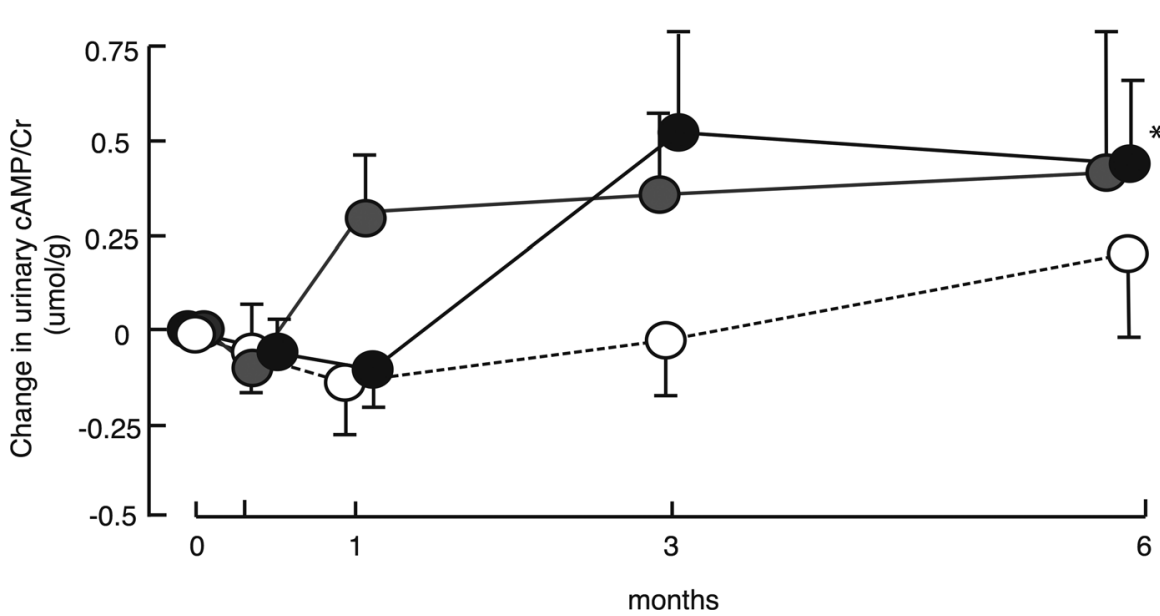


failure $(3,33)$. First-generation nonselective $\beta$-blockers are deleterious in heart failure, leading to an initial contraindication to their use. Selective $\beta_{1}$-blockers were developed and found to improve outcomes in clinical trials $(3,4,34)$. Later, with discovery of $\beta_{2}$-AR in cardiomyocytes, non-selective $\beta$-blockers were developed to block both $\beta_{1}$ - and $\beta_{2}$-ARs and the vasoconstrictive response through $\alpha$ blockade, i.e., $\beta$-blocker/ vasodilators. This drug class improved outcomes in heart failure in large clinical trials $(35,36)$. Carvedilol is a nonsubtype-selective $\beta$-blocker/vasodilator that has particularly beneficial effects in heart failure due to several unique features of effects. Lipid peroxidation is a major mechanism of myocardial tissue and endothelial injury in heart failure. Carvedilol, but not other $\beta$-blockers, scavenges free radicals and inhibits lipid peroxidation in myocardial cell membranes initiated by oxygen radicals $(37,38)$. Oxidative stress contributes to cardiomyocyte apoptotic death, and carvedilol inhibits apoptotic death $(39,40)$. Classical signaling through $\beta A R$ activation is through heterotrimeric $G$ proteins and the second messenger cAMP, but studies over the past decade show that the $\beta A R s$ exist in multiple active conformations with distinct signaling properties (41). $\beta$-Arrestins 1 and 2 bind to active phosphorylated $\beta$ ARs and terminate further receptor-stimulated $\mathrm{G}$ protein activation (42). Carvedilol stimulates $\beta$-arrestin-mediated signaling, which may account for many of its unique benefits (43). In addition, carvedilol was recently shown to cause vasodilation by increasing nitric oxide release from endothelial cells (44). The greater nitric oxide release from $\mathrm{PAH}$ endothelial cells with carvedilol is due to restoration of the endothelial nitric oxide synthase enzymatic activity (45). All these effects of carvedilol were important in our choice of $\beta$-blocker in PAHTCH. The dose of carvedilol chosen in this study was based on left heart failure studies (35). Like left heart failure, sympathetic hyperactivity is described in PAH and correlates with disease severity $(10,46)$. Ciarka et al. have shown that sympathetic hyperactivity is an independent predictor of clinical deterioration in PAH (46). Treatment with $\beta$-blockers in left heart failure decreases sympathetic activity, and decreases mortality; the dose of $\beta$-blocker is maximally adjusted to lower heart rate for best outcomes. In this study, carvedilol lowered the resting heart rate in $\mathrm{PAH}$ without affecting exercise capacity. Intriguingly, there were also benefits to the low-dose arm, suggesting that unlike left heart failure, RV failure in PAH may benefit from a low dose of carvedilol, perhaps related to its noncanonical effects on cardiomyocytes and endothelium.

Heart rate recovery after exercise testing has been shown to be a powerful and independent predictor of increased risk of death in all individuals (47). Exercise is associated with increased sympathetic and decreased parasympathetic activity, and the period of recovery after maximal exercise is characterized by a combination of sympathetic withdrawal and parasympathetic reactivation. Heart rate recovery after graded exercise is one of the commonly used techniques that reflects autonomic activity and predicts cardiovascular events and mortality (47). In PAH, heart rate recovery is a strong predictor of clinical worsening (48). In left heart disease, heart rate recovery is mediated by the vagal response rather than a chronotropic response. In a left heart failure study by Karnik et al., heart rate recovery was not different in patients treated with $\beta$-blockers compared with patients not on $\beta$-blockers (49). However, patients with positive stress tests, i.e., ischemia, had a blunted heart rate recovery that improved with $\beta$-blockade (49). The data suggest that an accelerated heart rate recovery after exercise in patients treated with $\beta$-blockers may be related to ischemia and/or an upregulation of $\beta$ ARs. Independent of the mechanism, the finding that carvedilol significantly accelerates heart rate recovery in PAH suggests that a longer-term study might identify differences in mortality in those individuals using carvedilol.

To quantitatively assess adherence to drug therapy, we measured $\beta$ ARs and levels of cAMP. These were used as markers of carvedilol therapy rather than outcomes of therapy. Similar to prior work in left heart failure (50), $\beta$ ARs increased in a dose-dependent manner with carvedilol. Cardiac and lymphocyte $\beta A R$ density have been shown to change in response to $\beta$-blocker therapy $(50,51)$; however, there are no studies correlating $\beta A R$ density on mononuclear cells to receptor density on cardiovascular cells. Similarly, urinary cAMP, a surrogate of $\beta$-adrenergic recovery, increased with carvedilol. Importantly, while these changes suggest adherence to drug therapy, their role in the mechanism of action in PAH needs further investigation. Effects of carvedilol on pathobiologic mechanisms of PAH were also evaluated. As in prior studies (23, 24, 27, 29), RV glycolytic uptake was increased in PAH hearts as compared with controls. This study now shows that carvedilol lowers RV glucose uptake relative to the LV. This could be related to improvements in blood flow to the myocardium, perhaps by decreasing metabolic load on the myocardium with $\beta$-blockade or to a decrease in afterload due to pulmonary vasodilation. Decreasing heart rate and systolic blood pressure with carvedilol will reduce oxygen consumption. In addition, $\beta$ ARs have recently been implicated in hypoxia sensing (52). Cheong et al. have shown that $\beta$-blockade suppresses hypoxic induction 
of gene expression, such as erythropoietin (52). Thus, $\beta$-blockade may also directly abrogate hypoxia sensing in the PAH myocardium. Here, erythropoietin levels did not change with carvedilol, but time and dose of drug may have been insufficient to see an effect.

This study has limitations. One limitation was the unexpected difference in age among the study groups, with the dose-escalating carvedilol group being older than the other 2 groups. This discrepancy in age occurred despite the fact that this was a randomized study. When analyzing the data, we adjusted for age in statistical analyses.

Another limitation of the study is the lack of invasive hemodynamic measurements at baseline and on follow up. The historical hemodynamics suggest some differences among the study groups. However, based on the data collected at baseline, the echocardiographic measurements are similar among the groups. Moreover, echocardiographic measurements suggest improved RV function and/or reduction in RV afterload on follow-up study visits; hemodynamics would have been the most reliable measure of safety and lack of decompensation in the treatment group. A larger study with hemodynamic measurements is warranted to more definitively confirm the safety of carvedilol in $\mathrm{PAH}$. Along these lines, another suggestion for future studies is to have patients undergo cardiopulmonary exercise testing in order to better understand the effects of carvedilol therapy and the reduction in heart rate on exercise.

A potential limitation in any oral treatment trial is adherence. Pill counts were performed at each study visit to detect errors or nonadherence. Even with this check, by the last study visit, 2 participants had stopped taking medications. Given this was an intention-to-treat study, those patients remained in their assigned groups for analysis. Dose de-escalation led to a lower number of patients on high-dose carvedilol by the end of the study. At the 6-month visit, only 5 patients were taking the maximum dose ( $25 \mathrm{mg}$ twice daily) of carvedilol. To address issues with adherence and dose reduction, urinary cAMP and $\beta A R$ were measured as surrogates of carvedilol effect.

Another limitation is numbers of participants and duration of this early-phase study. A larger sample size might have shown more significant changes. Furthermore, changes with $\beta$-blocker therapy become more pronounced over time in left heart disease; it is unclear what time period would be best to study $\beta$-blocker effects in PAH. A prospective study of larger numbers may require a 2-year longitudinal assessment. Likewise, the majority of participants in the study were within WHO group $1 \mathrm{PAH}$, with only 4 participants within WHO groups 3 and 4 . The group 3 participants had PH disproportionate to their lung disease and were on pulmonary vasodilators. The inclusion of non-group 1 subjects did not alter the effects of carvedilol on heart rate and RV metabolism. Although there were no apparent differences in response to carvedilol by PH type, further studies are needed to determine if responses vary by $\mathrm{PH}$ class.

Based on the current study, carvedilol is safe and has potential benefits linked to improved outcomes, such as accelerated heart rate recovery and lower RV glycolytic rate.

\section{Methods}

Selection of patients. Participants were 18 to 65 years of age, WHO functional class I, II, or III, with a diagnosis of idiopathic PAH, hereditary $\mathrm{PAH}$, or $\mathrm{PAH}$ associated with connective tissue disease, drugs, or toxins, human immunodeficiency virus, or repaired congenital heart defects (group 1 of the WHO classification of $\mathrm{PH}$ ), and $\mathrm{PH}$ WHO groups 3 and 4. Diagnosis of $\mathrm{PH}$ was confirmed by review of right heart catheterization showing a mean pulmonary arterial pressure of $25 \mathrm{mmHg}$ or greater and pulmonary vascular resistance more than 3 Wood units. Enrolled participants must have been stable on approved $\mathrm{PH}$ medications for the 30 days prior to enrollment. A full set of inclusion and exclusion criteria are provided in NCT01586156. All participants provided written informed consent. The target of the study was to enroll 30 participants, 10 in each arm.

Study intervention. After screening and consent, all eligible patients were admitted overnight to the Clinical Research Unit of the Cleveland Clinic to start the open-label challenge of carvedilol. If the patient tolerated this dose (assessed by symptoms and vital signs including blood pressure and pulse), the patient was then discharged home to continue on the drug at $3.125 \mathrm{mg}$ twice daily for the remainder of the week. A group of healthy controls was enrolled as a comparison group and underwent baseline testing. The control group was not part of the intervention study.

Patients were provided with a blood pressure monitor for home use and instructed to check their blood pressure and pulse as directed, and were contacted daily during the first week to check on vital 
signs and symptoms. Patients returned to clinic after 1 week. Patients who were able to complete the 1-week run-in phase without adverse effects were randomized in a 1:1:1 ratio to 1 of 3 arms for 24 weeks of treatment with placebo, low-fixed-dose carvedilol, or dose-escalating carvedilol to maximum tolerated dose. Blocked randomization was used. The block sizes were random and known only to the research pharmacist who performed the randomization and knew treatment assignment at time of enrollment. The first group received a placebo drug, the second group carvedilol at a fixed dose of $3.125 \mathrm{mg}$ twice daily, and the third group a weekly escalating dose of carvedilol to the maximal dose of $25 \mathrm{mg}$ twice daily. Participants continued to be treated by their PAH physicians as needed, including changes in dosing of their PAH medications.

Safety monitoring parameters were collected via weekly phone calls and at all follow-up visits. Subjects received weekly phone calls after starting the study and had study visits at week 1 and months 1,3 , and 6 to evaluate side effects, to monitor clinical status, and to collect outcome data. Patients were instructed to call if systolic blood pressure was less than $85 \mathrm{mmHg}$ or pulse was less than 55 , or if there were any adverse events such as hospitalization or unscheduled doctor visits. Subjects were asked whether they had experienced any side effects and to describe these symptoms, as well as to provide the blood pressure and heart rate home records, which were kept in the electronic medical record. Subjects were monitored throughout their enrollment, especially in regards to any deaths or hospitalizations during the study. Safety and tolerability outcomes and any other adverse events that occurred were recorded in the patient's electronic medical record. If a dose was not tolerated, the dose was decreased to the prior week's tolerated dose for the remainder of the study. A list of side effects that instigated a de-escalation of the dose is provided in Supplemental Table 3.

Any adverse events were investigated to identify possible etiology and relationship to study procedures and were reported to the IRB and the Data and Safety Monitoring (DSM) committee within 10 working days of their discovery, with the exception of any deaths, which were reported within 5 working days of their discovery.

Subjects were asked to bring the study medication and bottles with them to each follow-up visit. A tablet count was performed to estimate compliance. Subjects were also asked how many tablets per day they were taking on average, and how many times per week they had missed a dose. In addition, surrogate measures of adherence, including heart rate and cell surface $\beta$ ARs, were evaluated in the study.

Study assessments. Outcome data included safety, tolerability, clinical assessments of heart and lung functions, and biologic measures of pathologic hypoxia activation and endothelial dysfunction. Primary outcome was the measure of glucose uptake on cardiac FDG-PET scans. The various outcome data were collected at the baseline visit and at follow-up visits at week 1 and months 1, 3, and 6. Safety monitoring parameters were collected at all visits and via weekly phone calls throughout the study period.

The supplement includes all additional methods including echocardiogram, FDG-PET scan, and measurements of erythropoietin levels, $\beta$ AR, urinary cAMP, and NT-proBNP.

Outcome measures. The primary end point of the study was assessment of myocardial glucose uptake during fasting gated FDG-PET. FDG-PET scan measurements at week 24 were compared with baseline measurements. Prespecified secondary efficacy end points were changes from baseline in echocardiographic parameters, NT-proBNP level, 6-minute walk distance, WHO functional class, and CAMPHOR score. Safety assessments included laboratory measurements and evaluation of adverse events. All-cause mortality and hospitalizations were recorded for all participants in the study.

Dosing. To further evaluate the effect of carvedilol dosage on the different parameters and to account for compliance and de-escalation, we calculated the dose at each of the study visits per participant. The cumulative dose was calculated as the total dosage of carvedilol taken by the participant up to the visit day. The pill dose at time of the visit is the single dosage of medication taken at the time of the visit.

Statistics. The target total was 10 participants in each study arm. Sample size was determined by taking into account the power of a $t$ test comparing the placebo and carvedilol groups with respect to the reduction in FDG-PET uptake, as measured by the log-ratios of 6-month uptake to baseline uptake. Quantitative variables were summarized with means and standard deviations or medians and interquartile ranges as appropriate, while categorical variables were summarized as frequencies and percentages. The primary outcome and many secondary quantitative measures were anticipated to have positively skewed distributions, amenable to the use of log ratios of 1-, 3-, and 6-month measures relative to baseline to measure changes over time and achieve approximately normal distributions. For measures demonstrating less skewness or 


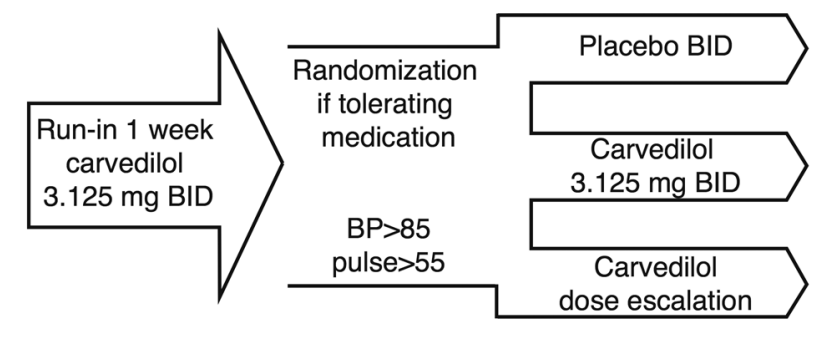

Figure 7. Pulmonary Arterial Hypertension Treatment with Carvedilol for Heart Failure (PAHTCH) study design. PAHTCH is a double-blind, randomized intervention with 3 arms. Patients able to complete the 1-week run-in phase of low-dose carvedilol were randomized to 1 of 3 arms for 24 weeks of treatment with placebo, fixed-low-dose carvedilol, or dose-escalating carvedilol to maximum tolerated dose. BID, twice daily. Subjects were followed over 6 months, with outcome data collected at baseline and at week 1 and months 1,3 , and 6 .

even approximate normality without log transformation, absolute changes from baseline to 1, 3, and 6 months were used to measure change over time. For quantitative measures in the randomized study groups, changes from baseline were compared using analysis of variance (ANOVA) at 0.05 significance levels, with pairwise group comparisons performed with 2-tailed $t$ tests at Bonferroni-adjusted significance levels. Within groups, changes were assessed for statistical significance using paired $t$ tests, with Bonferroni-adjusted significance levels applied when changes to multiple time points were considered. Covariate-adjusted comparisons were performed in the event that the randomized groups differed notably by any subject demographic characteristics. Associations among quantitative measures were assessed using Pearson correlations. For comparison of $\mathrm{PH}$ subjects with controls, 1 -sided $t$ test was used at 0.05 significance levels.

Study design and approval. The PAHTCH trial is a double-blinded, randomized, controlled intervention with 3 arms preceded by an open-label 1-week run-in period (Figure 7) (NCT01586156). It was conducted from 2012 to 2016 at the Cleveland Clinic. The IRB at Cleveland Clinic approved the study (number 11-1198). All participants provided informed consent prior to their participation in the study. A DSM committee composed of 3 physicians with expertise in heart failure and $\mathrm{PH}$ management and a biostatistician held scheduled meetings to maintain oversight of the trial progress. The study drug and placebo were prepared by the Cleveland Clinic Research pharmacy.

\section{Author contributions}

SF conducted the study, analyzed and interpreted data, and wrote the manuscript. DS conducted studies and collected and analyzed data. MMP performed and read echocardiographies and collected data. HIC performed research experiment and analyzed and interpreted data. KA performed research and analyzed and interpreted data and reviewed the manuscript. SAAC collected data and samples and put in place the database. ORS performed research experiments and analyzed data. ECR conducted studies and collected data. JS recruited patients. KBH conducted studies and reviewed the manuscript. FPD analyzed PET data. DRN read and analyzed imaging data. WHWT analyzed data and reviewed the manuscript. SCE designed research, analyzed data, and wrote the manuscript.

\section{Acknowledgments}

We thank Allison Janocha for editorial assistance, Kimberly Queisser for assistance with blood samples processing, and Joseph Gerow and Eric Schultz from the LRI Flow Cytometry Core for instrument setup and daily quality controls. We thank the DSM committee: David Taylor, James Thomas, Raed Dweik, and Jeff Hammel, for careful oversight of the study.

Address correspondence to: Samar Farha or Serpil Erzurum, Cleveland Clinic, 9500 Euclid Avenue, NB21, Cleveland, Ohio 44195, USA. Phone: 216.445.6624; Email: farhas@ccf.org (S. Farha); erzurus@ccf.org (S. Erzurum).

\footnotetext{
1. van de Veerdonk MC, et al. Progressive right ventricular dysfunction in patients with pulmonary arterial hypertension responding to therapy. J Am Coll Cardiol. 2011;58(24):2511-2519.

2. van de Veerdonk MC, Bogaard HJ, Voelkel NF. The right ventricle and pulmonary hypertension. Heart Fail Rev. 2016;21(3):259-271

3. Bristow MR. Treatment of chronic heart failure with $\beta$-adrenergic receptor antagonists: a convergence of receptor pharmacology and clinical cardiology. Circ Res. 2011;109(10):1176-1194.

4. Hjalmarson A, et al. Effects of controlled-release metoprolol on total mortality, hospitalizations, and well-being in patients with
} 
heart failure: the Metoprolol CR/XL Randomized Intervention Trial in congestive heart failure (MERIT-HF). MERIT-HF Study Group. JAMA. 2000;283(10):1295-1302.

5. Chatterjee $\mathrm{S}$, et al. Benefits of $\beta$ blockers in patients with heart failure and reduced ejection fraction: network meta-analysis. BMJ. 2013;346:f55.

6. Perros F, et al. Use of $\beta$-blockers in pulmonary hypertension. Circ Heart Fail. 2017;10:e003703.

7. Provencher S, et al. Deleterious effects of beta-blockers on exercise capacity and hemodynamics in patients with portopulmonary hypertension. Gastroenterology. 2006;130(1):120-126.

8. Peacock A, Ross K. Pulmonary hypertension: a contraindication to the use of $\{$ beta $\}$-adrenoceptor blocking agents. Thorax. 2010;65(5):454-455.

9. Wisenbaugh T, et al. Pulmonary hypertension is a contraindication to beta-blockade in patients with severe mitral stenosis. $A m$ Heart J. 1993;125(3):786-790.

10. Velez-Roa S, Ciarka A, Najem B, Vachiery JL, Naeije R, van de Borne P. Increased sympathetic nerve activity in pulmonary artery hypertension. Circulation. 2004;110(10):1308-1312.

11. Nagaya N, et al. Plasma brain natriuretic peptide as a prognostic indicator in patients with primary pulmonary hypertension. Circulation. 2000;102(8):865-870.

12. Nootens $\mathrm{M}$, et al. Neurohormonal activation in patients with right ventricular failure from pulmonary hypertension: relation to hemodynamic variables and endothelin levels. J Am Coll Cardiol. 1995;26(7):1581-1585.

13. Bristow MR, et al. Beta-adrenergic neuroeffector abnormalities in the failing human heart are produced by local rather than systemic mechanisms. J Clin Invest. 1992;89(3):803-815.

14. Schrier RW, Bansal S. Pulmonary hypertension, right ventricular failure, and kidney: different from left ventricular failure? Clin $J$ Am Soc Nephrol. 2008;3(5):1232-1237.

15. Rose JA, et al. Flow cytometric quantification of peripheral blood cell $\beta$-adrenergic receptor density and urinary endothelial cell-derived microparticles in pulmonary arterial hypertension. PLoS ONE. 2016;11(6):e0156940.

16. Perros F, et al. Nebivolol for improving endothelial dysfunction, pulmonary vascular remodeling, and right heart function in pulmonary hypertension. J Am Coll Cardiol. 2015;65(7):668-680.

17. Bogaard HJ, et al. Adrenergic receptor blockade reverses right heart remodeling and dysfunction in pulmonary hypertensive rats. Am J Respir Crit Care Med. 2010;182(5):652-660.

18. Bandyopadhyay D, Bajaj NS, Zein J, Minai OA, Dweik RA. Outcomes of $\beta$-blocker use in pulmonary arterial hypertension: a propensity-matched analysis. Eur Respir J. 2015;46(3):750-760.

19. Grinnan D, et al. Treatment of group I pulmonary arterial hypertension with carvedilol is safe. Am J Respir Crit Care Med. 2014;189(12):1562-1564.

20. van Campen JS, et al. Bisoprolol in idiopathic pulmonary arterial hypertension: an explorative study. Eur Respir J. 2016;48(3):787-796.

21. So PP, et al. Usefulness of beta-blocker therapy and outcomes in patients with pulmonary arterial hypertension. Am J Cardiol. 2012;109(10):1504-1509.

22. Bouallal R, Godart F, Francart C, Richard A, Foucher-Hossein C, Lions C. Interest of $\beta$-blockers in patients with right ventricular systemic dysfunction. Cardiol Young. 2010;20(6):615-619.

23. Lundgrin EL, et al. Fasting 2-deoxy-2-[18F]fluoro-D-glucose positron emission tomography to detect metabolic changes in pulmonary arterial hypertension hearts over 1 year. Ann Am Thorac Soc. 2013;10(1):1-9.

24. Saygin D, et al. Metabolic and functional evaluation of the heart and lungs in pulmonary hypertension by gated 2-[18F]-fluoro2-deoxy-D-glucose positron emission tomography. Pulm Circ. 2017;7(2):428-438.

25. Xu W, et al. Alterations of cellular bioenergetics in pulmonary artery endothelial cells. Proc Natl Acad Sci USA. 2007;104(4):1342-1347.

26. Hagan G, et al. (18)FDG PET imaging can quantify increased cellular metabolism in pulmonary arterial hypertension: A proofof-principle study. Pulm Circ. 2011;1(4):448-455.

27. Can MM, et al. Increased right ventricular glucose metabolism in patients with pulmonary arterial hypertension. Clin Nucl Med. 2011;36(9):743-748

28. Piao L, et al. The inhibition of pyruvate dehydrogenase kinase improves impaired cardiac function and electrical remodeling in two models of right ventricular hypertrophy: resuscitating the hibernating right ventricle. $J$ Mol Med. 2010;88(1):47-60.

29. Graham BB, et al. Severe pulmonary hypertension is associated with altered right ventricle metabolic substrate uptake. Am J Physiol Lung Cell Mol Physiol. 2015;309(5):L435-L440.

30. McKenna SP, Doughty N, Meads DM, Doward LC, Pepke-Zaba J. The Cambridge Pulmonary Hypertension Outcome Review (CAMPHOR): a measure of health-related quality of life and quality of life for patients with pulmonary hypertension. Qual Life Res. 2006;15(1):103-115.

31. Gomberg-Maitland M, Thenappan T, Rizvi K, Chandra S, Meads DM, McKenna SP. United States validation of the Cambridge Pulmonary Hypertension Outcome Review (CAMPHOR). J Heart Lung Transplant. 2008;27(1):124-130.

32. Steinberg SF. The molecular basis for distinct beta-adrenergic receptor subtype actions in cardiomyocytes. Circ Res. 1999;85(11):1101-1111.

33. Bristow MR. Beta-adrenergic receptor blockade in chronic heart failure. Circulation. 2000;101(5):558-569.

34. A randomized trial of beta-blockade in heart failure. The Cardiac Insufficiency Bisoprolol Study (CIBIS). CIBIS Investigators and Committees. Circulation. 1994;90(4):1765-1773.

35. Packer M, et al. The effect of carvedilol on morbidity and mortality in patients with chronic heart failure. U.S. Carvedilol Heart Failure Study Group. N Engl J Med. 1996;334(21):1349-1355.

36. Packer M, et al. Effect of carvedilol on survival in severe chronic heart failure. N Engl J Med. 2001;344(22):1651-1658

37. Yue TL, et al. Carvedilol, a new vasodilator and beta adrenoceptor antagonist, is an antioxidant and free radical scavenger J Pharmacol Exp Ther. 1992;263(1):92-98.

38. Ruffolo RR, Feuerstein GZ. Pharmacology of carvedilol: rationale for use in hypertension, coronary artery disease, and congestive heart failure. Cardiovasc Drugs Ther. 1997;11 Suppl 1:247-256. 
39. Rössig L, et al. Congestive heart failure induces endothelial cell apoptosis: protective role of carvedilol. J Am Coll Cardiol. 2000;36(7):2081-2089.

40. Maggi E, Marchesi E, Covini D, Negro C, Perani G, Bellomo G. Protective effects of carvedilol, a vasodilating beta-adrenoceptor blocker, against in vivo low density lipoprotein oxidation in essential hypertension. J Cardiovasc Pharmacol. 1996;27(4):532-538.

41. Yang J, Liu Y, Fan X, Li Z, Cheng Y. A pathway and network review on beta-adrenoceptor signaling and beta blockers in cardiac remodeling. Heart Fail Rev. 2014;19(6):799-814.

42. Benovic JL, Kühn H, Weyand I, Codina J, Caron MG, Lefkowitz RJ. Functional desensitization of the isolated beta-adrenergic receptor by the beta-adrenergic receptor kinase: potential role of an analog of the retinal protein arrestin (48-kDa protein). Proc Natl Acad Sci USA. 1987;84(24):8879-8882.

43. Wisler JW, et al. A unique mechanism of beta-blocker action: carvedilol stimulates beta-arrestin signaling. Proc Natl Acad Sci USA. 2007;104(42):16657-16662.

44. Kalinowski L, et al. Third-generation beta-blockers stimulate nitric oxide release from endothelial cells through ATP efflux: a novel mechanism for antihypertensive action. Circulation. 2003;107(21):2747-2752.

45. Ghosh S, et al. Phosphorylation inactivation of endothelial nitric oxide synthesis in pulmonary arterial hypertension. Am $J$ Physiol Lung Cell Mol Physiol. 2016;310(11):L1199-L1205.

46. Ciarka A, Doan V, Velez-Roa S, Naeije R, van de Borne P. Prognostic significance of sympathetic nervous system activation in pulmonary arterial hypertension. Am J Respir Crit Care Med. 2010;181(11):1269-1275.

47. Cole CR, Blackstone EH, Pashkow FJ, Snader CE, Lauer MS. Heart-rate recovery immediately after exercise as a predictor of mortality. N Engl J Med. 1999;341(18):1351-1357.

48. Minai OA, Gudavalli R, Mummadi S, Liu X, McCarthy K, Dweik RA. Heart rate recovery predicts clinical worsening in patients with pulmonary arterial hypertension. Am J Respir Crit Care Med. 2012;185(4):400-408.

49. Karnik RS, Lewis W, Miles P, Baker L. The effect of beta-blockade on heart rate recovery following exercise stress echocardiography. Prev Cardiol. 2008;11(1):26-28.

50. Waagstein F, Caidahl K, Wallentin I, Bergh CH, Hjalmarson A. Long-term beta-blockade in dilated cardiomyopathy. Effects of short- and long-term metoprolol treatment followed by withdrawal and readministration of metoprolol. Circulation. 1989;80(3):551-563.

51. Aarons RD, Nies AS, Gal J, Hegstrand LR, Molinoff PB. Elevation of beta-adrenergic receptor density in human lymphocytes after propranolol administration. J Clin Invest. 1980;65(5):949-957.

52. Cheong HI, et al. Hypoxia sensing through $\beta$-adrenergic receptors. JCI Insight. 2016;1(21):e90240. 